\title{
Red Blood Cell Distribution Width in Acute Coronary Syndromes
}

\author{
L De Biase*, F Jacoangeli, G Viola, S Abbolito, A Romaniello, G Scillitani, A Tonino, \\ E Mencarelli, C Autore, M Volpe
}

Cardiology, Department of Clinical and Molecular Medicine, Sapienza University, Rome, Italy

\begin{abstract}
Objective: RDW is a measure of the variation of red blood cell width, reported as part of standard complete blood count; many paper reported results about the role of RDW in heart failure; the role of RDW in Acute Coronary Syndromes (ACS) is less known.

Methods: We enrolled 173 consecutive patients, admitted to the coronary care unit of our hospital, with a diagnosis of obstructive ACS, documented by the evidence of obstructive coronary lesions on coronary angiography. We divided patients into two Groups: Group 1, with normal values of RDW; Group 2, with RDW values higher than normal range. Ventricular systolic function, was measured with echocardiography. Results: Patients of group 1 had a greater Ejection Fraction $(p=0.03)$ and lower values of NT-proBNP $(p=0.001)$. Finally we found a lower eGFR in patients of group 2 , than in patients of group $1(\mathrm{p}=0.0001)$.

Conclusions: Our results suggest that RDW is a routine and inexpensive test that can provide information concerning severity of clinical condition in acute phase of an ACS, both as regards the cardiac contractility, both with regard to renal function. These variables are important prognostic factors in patients after ACS.
\end{abstract}

Keywords: RDW, Acute Coronary Syndrome, Ejection Fraction, NT-proBNP, Killip Class, Renal Function.

\section{INTRODUCTION}

Red blood cells distribution width (RDW) is a measure of red blood cell width variation, reported as part of a standard complete blood count; although it is usually measured, as a routine test, actually its values have been only used in the differential diagnosis of anaemia and high values indicate the presence of anisocytosis [1].

Recently it has been demonstrated that RDW could be considered an independent prognostic marker of cardiovascular events in patients with heart failure and peripheral artery diseases $[1,2]$.

Some Authors studied the role or RDW as a predictor of mortality in patients with heart failure [3, 4]; others analyzed the relation between NT-proBNP and RDW in these patients [5]; however the role of RDW in patients with acute coronary syndromes (ACS) is less known; there are in literature some data regarding the role of RDW in short-term outcomes in these patients [6]; some authors analyzed sixmonths outcomes, finding an independent association between higher RDW values and adverse outcomes [7].

However, the mechanism by which RDW is related to a poor prognosis in patients with ACS is still unclear.

Our aim was to study the pattern of RDW in the acute phase of an ACS and its relationship with other variables.

*Address correspondence to these authors at the Cardiology, Department of Clinical and Molecular Medicine, Sapienza University, Via di Grottarossa 1037, 00189, Rome, Italy; Tel: 06/33775563; Fax: 06/33775061;

E-mail: luciano.debiase@uniroma1.it

\section{MATERIALS AND METHODS}

In our prospective study we enrolled 171 consecutive patients, admitted to the coronary care unit of our hospital between October 2011 and September 2012. The study was approved by the ethical committee of our hospital.

Patients were included in the analysis if they had a diagnosis of acute coronary syndrome documented by the evidence of obstructive coronary lesions on coronary angiography.

Our population included patients with unstable angina, non-ST-segment elevation myocardial infarction (NSTEMI), ST-segment elevation myocardial infarction (STEMI).

Clinical and biochemical data of each patient were collected in an electronic database. All patients referred had a full medical history (with information regarding lifestyle, clinical history, cardiovascular risk factors, presence of other pathologies like renal failure and diabetes mellitus), a physical examination, an echocardiogram, a 12-lead electrocardiogram, a coronary angiography; routine blood tests, including a complete blood count, myocardial necrosis markers, lipid profile, CRP, thyroid profile, renal function profile were carried out by our biochemistry department.

In our laboratory, normal reference range of RDW in human blood is $11.6-14.6 \%$.

We divided the population in two groups, depending on RDW values: Group 1, including patients with normal values of RDW; Group 2, including patients with RDW values over the normal range. 
Table 1. General Characteristics of Population

\begin{tabular}{|l|c|c|c|}
\hline & Group1 & Group2 & P Value \\
\hline \hline Total number & 104 & 67 & $\mathrm{p}=0.23$ \\
\hline Hypertension & $74 \%$ & $82 \%$ & $\mathrm{p}=0.64$ \\
\hline Present or past smoke habits & $67 \%$ & $71 \%$ & $\mathrm{p}=1.00$ \\
\hline Dyslipidemia & $73 \%$ & $73 \%$ & $\mathrm{p}=0.49$ \\
\hline BMI $>30$ & $24 \%$ & $19 \%$ & $\mathrm{p}=0.36$ \\
\hline DMII & $29 \%$ & $36 \%$ & \\
\hline
\end{tabular}

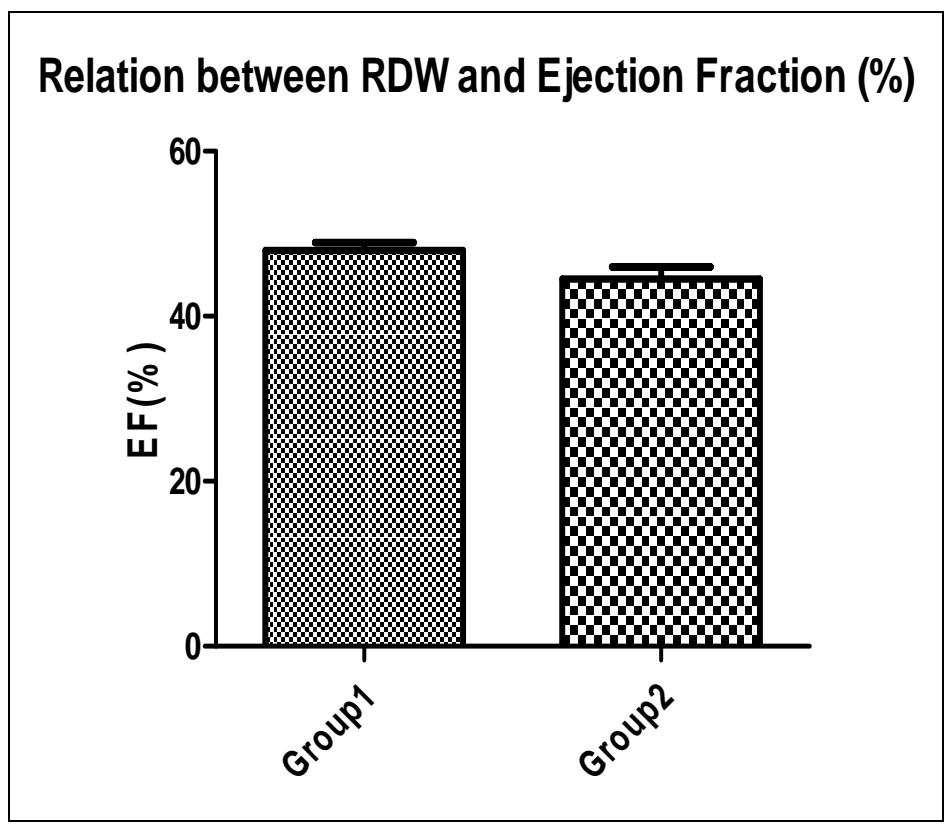

Fig. (1). Relationship between RDW and Ejection Fraction.

\section{STATISTIC ANALYSIS}

Data analysis was performed using the GraphPad Prism 5.

Continuous variables are presented as mean \pm standard deviation and were compared using Student's unpaired test. Categorical variables are presented as frequency counts and percentages and were calculated with the "Chi-square" test when appropriate; otherwise, Fisher's exact test was used.

$P$ value equal or less than 0.05 was considered statistically significant.

\section{RESULTS}

\section{Patients Characteristics}

The baseline characteristics of population are described in Table 1.

Of the 171 patients who were enrolled, 104 were included in group 1, while 67 were included in group 2. Patient with high RDW values were significantly older (group 1: $64.44 \mathrm{y} \pm 1.118$; group $2: 68.93 \mathrm{y} \pm 1.263 ; \mathrm{p}=0.01)$, with a greater percentage of female patients $(29 \%$ in group $2 ; 16 \%$ in group 1). The two groups were comparable regarding prevalence of hypertension, dyslipidemia, obesity, diabetes mellitus, smoking habits and domiciliary pharmacological treatment.

\section{RDW and Left Ventricular Systolic Function}

The left ventricular systolic function of two groups of patients was analyzed, by measuring the Ejection Fraction (EF) with echocardiography and a greater EF we found in patients of group 1 (mean values: $47.98 \% \pm 0.9520$ ), than in patients belonging to group 2 (mean values $44.52 \% \pm 1.469$ ); the difference was statistically significant: $\mathrm{p}=0.03$, Fig. (1).

Moreover, only $4 \%$ of patients belonging to group 1 had an EF lower than $30 \%$, instead of $22 \%$ of patients belonging to group 2 .

\section{RDW and NT-proBNP}

$\mathrm{N}$-terminal brain natriuretic peptide (NT-proBNP) levels were measured in each patient the day after the admission in our intensive care unit: comparing values of two groups we found a statistically significant difference $(\mathrm{p}=0.001)$, with greater values of NT-proBNP in patients of group 2 (mean 


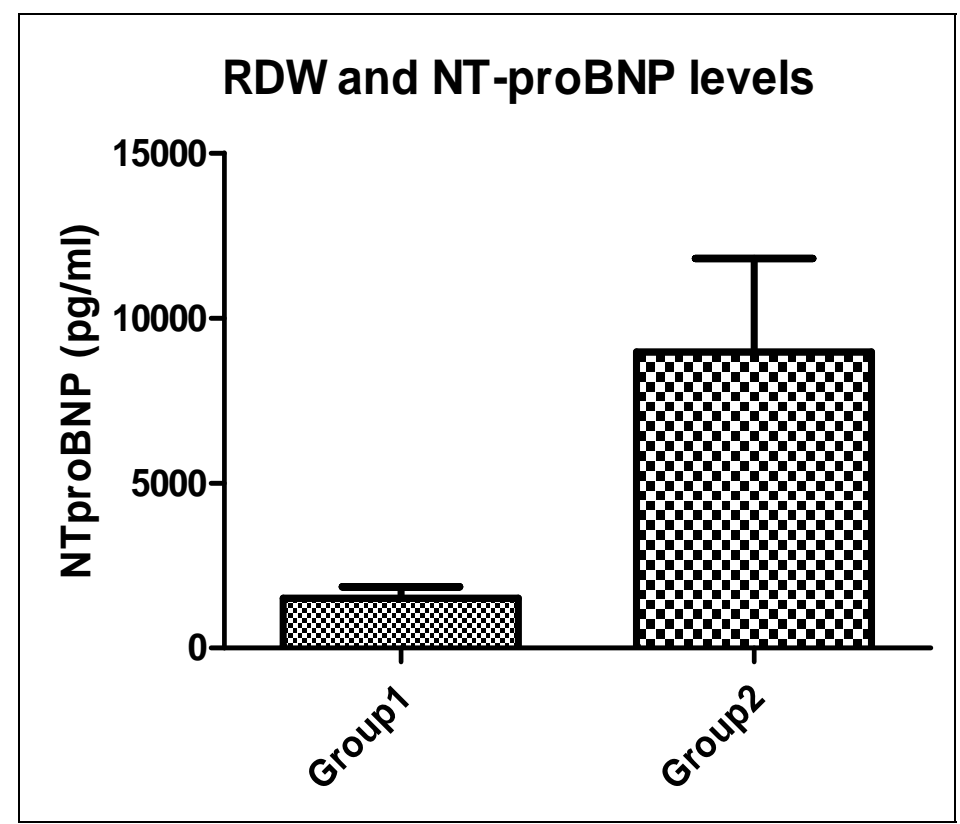

Fig. (2). Relationship between RDW and NT-proBNP levels.

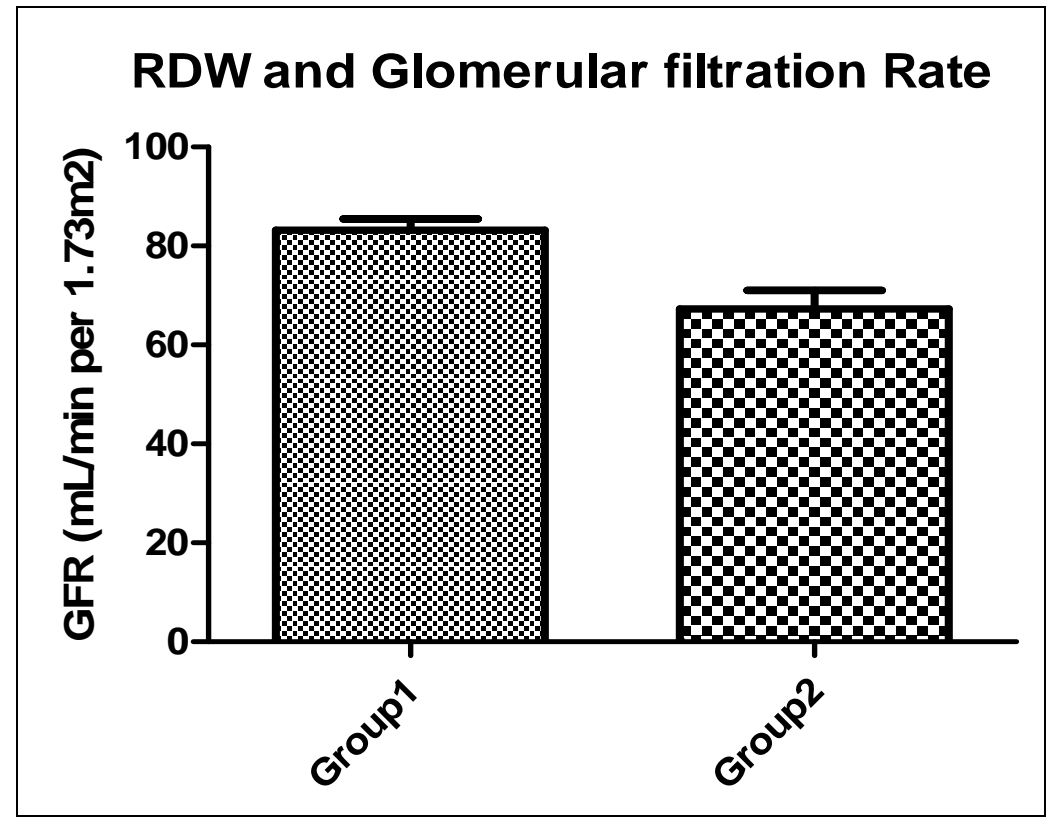

Fig. (3). Relationship between RDW and GFR.

values: $8973 \mathrm{pg} / \mathrm{ml} \pm 2831$ ), than in patients of group 1 (mean values: $1505 \mathrm{pg} / \mathrm{ml} \pm 349.4$ ); Fig. (2).

\section{RDW and Estimated Glomerular Filtration Rate}

A possible relation between high value of RDW and renal function was analyzed; the glomerular filtration rate (eGFR) of each patient was measured by calculating it with CKD-EPI formula; our data showed a lower eGFR in patients of group 2, than in patients of group 1 (mean values of group1: $83.24 \mathrm{ml} / \mathrm{min} / 1,73 \mathrm{~m}^{2} \pm 2.181$; group 2: 67.27 $\mathrm{ml} / \mathrm{min} / 1,73 \mathrm{~m}^{2} \pm 3.786 ; \mathrm{p}=0.0001 ;$ (Fig. 3).

\section{DISCUSSION}

The role of RDW in patients with acute coronary syndrome has not been investigated as well as its role in patients with heart failure.

Many papers have demonstrated the role of RDW in patients with heart failure: according to Al-Najjar http://eurjhf.oxfordjournals.org/content/11/12/1155. long corresp-1 et al. [8], RDW has an independent prognostic power in these patients. They analyzed a cohort of patients with heart failure, comparing power of RDW with NT- 
proBNP, and they suggested that the two factors can be considered similar in predicting cardiovascular events, and independent from each other.

Moreover, the role of RDW as a predictor of mortality in patients with heart failure was investigated: Pascual-Figal et al analyzed a cohort of 628 consecutive patients with acute heart failure finding that higher RDW levels at discharge were associated with worse long-term outcome regardless of haemoglobin levels and anaemia status (3). A role in the prognosis was established also for patients with diastolic heart failure in a study on the relationship between RDW and NT-proBNP [9].

However, there is evidence that RDW could be considered a predictor of death and other cardiovascular events also in patients with coronary artery diseases, as Tonelli et al have shown [10]; other studies confirmed these results: Wang et al analyzed the role of RDW in short-term outcomes in patients with ACS in a chinese population: they enrolled 1654 patients with ACS, dividing them into four groups according to quartiles of baseline RDW and they found that elevated RDW calues could predict an increased risk of short-term adverse outcomes in these patients [6].

However, nowadays there are no evidence about the possible mechanism that leads to a poorer prognosis in patients with ACS.

In literature, there is also evidence of the relation between RDW and renal function: Forhècz et al studied 195 patients with systolic heart failure to validate recent observations on the predictive role of RDW for outcomes in chronic heart failure; during this observational study, they found that RDW was correlated to an ineffective erythropoiesis, undernutrition and impaired renal function [11]; according to these data, Lippi et al studied 8585 adult outpatients over a 3-year period and they found an inverse, graded, association between RDW and kidney function [12].

Our results suggest that RDW can provide information concerning the severity of clinical condition in the acute phase of an ACS and a relation with poor prognostic factors as a reduced systolic function and an impaired glomerular filtration rate; these data confirmed evidence of literature, according to which RDW should be related to heart failure and to a lower renal function.

In our opinion, these evidences could partially explain the poorer prognosis of patients with ACS and elevated levels of RDW, characterized by a greater prevalence of mortality and new cardiovascular events, as reported in literature.

\section{CONCLUSIONS}

Since this measurement of RDW is included in the routine tests to which every patient admitted to the hospital should be submitted, as part of peripheral blood counts,
RDW appears to be a non expensive and easy to obtain variable that should be taken into account in the overall assessment of patients with ACS, both during the acute phase of an ACS, and during follow-up of these patients.

\section{CONFLICT OF INTEREST}

The authors confirm that this article content has no conflicts of interest.

\section{ACKNOWLEDGEMENT}

Declared none.

\section{REFERENCES}

[1] Tsuboi S, Miyauchi K, Kasai T, et al. Impact of Red Blood Cell Distribution Width on Long-Term Mortality in Diabetic Patients After Percutaneous Coronary Intervention. Circ J 2013; 77(2): 45661.

[2] Nishizaki Y, Yamagami S, Suzuki H, et al. Red blood cell distribution width as an effective tool for detecting fatal heart failure in super-elderly patients. Intern Med 2012; 51(17): 2271-6.

[3] Pascual-Figal DA, Bonaque JC, Redondo B, et al. Red blood cell distribution width predicts long-term outcome regardless of anaemia status in acute heart failure patients. Eur J Heart Fail 2009; 11(9): 840-6.

[4] Felker GM, Allen LA, Pocock SJ, et al. Red cell distribution width as a novel prognostic marker in heart failure: data from the CHARM Program and the Duke Databank. J Am Coll Cardiol 2007; 50(1): 40-7.

[5] Holmström A, Sigurjonsdottir R, Hammarsten O, Gustafsson D, Petzold M, Fu ML. Red blood cell distribution width and its relation to cardiac function and biomarkers in a prospective hospital cohort referred for echocardiography. Eur J Intern Med 2012; 23(7): 604-9.

[6] Wang YL, Hua Q, Bai CR, Tang Q. Relationship between red cell distribution width and short-term outcomes in acute coronary syndrome in a Chinese population. Intern Med 2011; 50(24): 2941-5. Epub 2011 Dec 15.

[7] Nabais S, Losa N, Gaspar A, et al. Association between red blood cell distribution width and outcomes at six months in patients with acute coronary syndromes. Rev Port Cardiol 2009; 28(9): 905-24.

[8] Al-Najjar Y, Goode KM, Zhang J, Cleland JG, Clark AL. Red cell distribution width: an inexpensive and powerful prognostic marker in heart failure. Eur J Heart Fail 2009; 11(12): 1155-62.

[9] Celik A, Koc F, Kadi H, et al. Relationship between red cell distribution width and echocardiographic parameters in patients with diastolic heart failure. Kaohsiung J Med Sci 2012; 28(3): 165-72.

[10] Tonelli M, Sacks F, Arnold M, Moye L, Davis B, Pfeffer M; for the Cholesterol and Recurrent Events (CARE) Trial Investigators. Relation Between Red Blood Cell Distribution Width and Cardiovascular Event Rate in People With Coronary Disease. Circulation 2008; 117(2): 163-8.

[11] Forhecz Z, Gombos T, Borgulya G, Pozsony Z, Janoskuti L. Red cell distribution width in heart failure: prediction of clinical events and relationship with markers of ineffective erytropoiesis, inflammation, renal function, and nutritional state. Am Heart J 2009; 158 (4) : 659-66.

[12] Lippi G, Targher G, Montagnana M, Salvagno GL, Zoppini G, Guidi GC. Relationship between red blood cell distribution width and kidney function tests in a large cohort of unselected outpatients. Scand J Clin Lab Invest 2008; 68(8): 745-8. 